\title{
Neighbour-stranger call discrimination in a nocturnal rail species, the Corncrake Crex crex
}

\author{
Michał Budka • Tomasz S. Osiejuk
}

Received: 5 January 2012/Revised: 3 January 2013/Accepted: 14 January 2013/Published online: 6 February 2013

(C) The Author(s) 2013. This article is published with open access at Springerlink.com

\begin{abstract}
The acoustic signals of birds are commonly used for individual recognition. Calls or songs allow discrimination between parent and offspring, between mates and between territorial neighbours and strangers. In this study, we investigated vocal neighbour-stranger discrimination in a nocturnally calling rail species, the Corncrake, Crex crex. We conducted interactive playback experiments with 43 males. All males were tested twice on the same night, and their responses to the calls of a familiar neighbour and the calls of an unfamiliar stranger were measured. The Corncrake males responded more aggressively to the playback of a stranger's calls. They approached the speaker more rapidly, spent more time close to the speaker and physically attacked the speaker more frequently. We found no significant differences between the vocal responses to the playback of neighbours' and strangers' calls. Thus, although calling plays an important role in Corncrake territorial interactions, it is only a first line of defence in which males signal aggression towards intruders by calling, similar to singing in passerines. The lack of differences in vocal responses and the presence of clear differences in other behavioural responses demonstrate that the absence of a differential vocal response does not imply the absence of discrimination. Although the individual nature of the Corncrake call has been mentioned in a few previous studies, this study provides the first experimental evidence that Corncrake males indeed use calls for neighbour-stranger discrimination.
\end{abstract}

Communicated by F. Bairlein.

M. Budka $(\bowtie) \cdot$ T. S. Osiejuk

Department of Behavioural Ecology, Institute of Environmental

Biology, Faculty of Biology, Adam Mickiewicz University,

Umultowska 89, 61614 Poznan, Poland

e-mail: m.budka@amu.edu.pl
Notably, because of the Corncrake's dense wet meadow habitat and its tendency to signal at night, it is probable that acoustic individual discrimination in the Corncrake is crucial for making correct decisions during aggressive encounters with rivals.

Keywords Neighbour-stranger discrimination - Dear enemy phenomenon · Call · Vocalisation · Playback experiment

\section{Zusammenfassung}

Rufunterscheidung zwischen Reviernachbarn und fremden Individuen beim Wachtelkönig Crex crex einer nachtaktiven Rallenart

Vögel nutzen akustische Signale häufig zur Individualerkennung. Rufe oder Gesänge ermöglichen die Unterscheidung von Eltern und Jungvögeln, zwischen Partnern sowie von Reviernachbarn und fremden Individuen. In dieser Studie untersuchten wir die stimmliche Unterscheidung von Nachbarn und Fremden bei einer nächtlich rufenden Rallenart, dem Wachtelkönig Crex crex. Wir führten interaktive Playback-Versuche an 43 Männchen durch. Für alle Männchen machten wir den Test zweimal in derselben Nacht und erfassten die jeweiligen Reaktionen auf die Rufe eines vertrauten Nachbarn beziehungsweise auf die Rufe eines unbekannten Tieres. Die Wachtelkönig-Männchen reagierten aggressiver auf das Vorspielen fremder Rufe. Sie näherten sich dem Lautsprecher schneller, verbrachten mehr Zeit in dessen Nähe und griffen diesen häufiger an. Zwischen den Rufantworten auf das Vorspielen von Rufen von Nachbarn beziehungsweise Fremden fanden wir allerdings keine signifikanten Unterschiede. Obwohl also das Rufen eine wichtige Rolle bei den territorialen Interaktionen 
der Wachtelkönige spielt, stellt dies quasi nur eine erste Verteidigungslinie dar, bei der die Männchen durch ihr Rufen gegenüber Eindringlingen aggressiv auftreten, vergleichbar mit dem Gesang von Singvögeln. Die fehlenden Unterschiede in den Rufantworten und das gleichzeitige Vorhandensein deutlicher Unterschiede in den übrigen Reaktionsverhaltensweisen zeigen, dass das Fehlen einer differenzierten Rufantwort nicht gleichbedeutend mit mangelnder Unterscheidungsfähigkeit ist. Obgleich der individuelle Charakter des Wachtelkönig-Rufes bereits in einigen früheren Arbeiten erwähnt wurde, liefert diese Studie den ersten experimentellen Nachweis, dass männliche Wachtelkönige tatsächlich Rufe zur Unterscheidung von Nachbarn und Fremden heranziehen. Vor allem aufgrund des dichten Feuchtwiesenhabitats des Wachtelkönigs und seiner vorwiegend nächtlichen Rufaktivität ist es wahrscheinlich, dass die akustische Individualerkennung für den Wachtelkönig eine wichtige Entscheidungshilfe bei aggressiven Begegnungen mit Rivalen darstellt.

\section{Introduction}

The defence of access to limited resources, such as refuges, mates, nest sites or food, produces benefits for the individual. Simultaneously, high costs related to patrolling, chasing intruders, signalling, the risk of predation and the risk of injury are generated. If the benefits from exclusive access to limited resources exceed the costs of defence, territoriality is observed (Brown 1964). The possibility of recognition between familiar neighbours and unfamiliar strangers can reduce the costs of territorial defence by preventing unnecessary conflicts with familiar individuals (Temeles 1994). Neighbours do not necessarily constitute a serious threat to the territory holder, whereas any stranger could be a potential rival seeking a territorial insertion or takeover. Therefore, after the borders of the territory are established, the reaction of the territory-holder to an intrusion by a familiar neighbour should be less aggressive than the reaction to an intrusion by a stranger. This reduction of aggression towards a neighbour has been termed the "dear enemy phenomenon" (Fisher 1954) and has been observed in numerous territorial species, including mammals, birds, reptiles, amphibians and insects (Davis 1987; Temeles 1994). However, a "dear enemy" relationship may be flexible and may evolve with the social and ecological circumstances (Briefer et al. 2008b). In certain cases, a neighbour can be more threatening than a stranger (Temeles 1990). Moreover, the presence of a female within a male's territory can modify the male's aggressive responses to neighbours and strangers (Leiser 2003). Neighbours can be treated as a dear enemy only in the middle of the breeding season, when territories are stable, but not at the beginning and at the end of the season (Briefer et al. 2008b). Moreover, a group signature can be used by birds for neighbour-stranger discrimination (Briefer et al. 2008a). In the above-mentioned situations, intrusions of neighbours or strangers represent varying levels of threat to the territory-holder. A different response should therefore be observed if the ability to recognise individuals is present.

In birds, acoustic signals are commonly used in individual recognition (Catchpole and Slater 2008). Calls or songs enable discrimination between parent and offspring (Jouventin et al. 1999), between mates (Clark et al. 2006) and between territorial neighbours and strangers (Stoddard 1996). neighbour-stranger discrimination (hereafter NSD) in a territorial-defence context has been studied primarily in songbirds, Oscines, i.e. birds acquiring a song through learning during ontogeny (Stoddard 1996). Relatively little is known about NSD in non-learning bird species. Only a few studies have presented evidence for NSD in grouse (Falls and McNicholl 1979), tyrant flycatchers (Lovell and Lein 2004), shearwaters (Mackin 2005), loons (Mager et al. 2010), wood hoopoes (Radford 2005) and owls (Hardouin et al. 2006). Furthermore, several researchers have suggested the potential occurrence of NSD based on individually specific call characteristics in non-learners (e.g. Peake et al. 1998; Rebbeck et al. 2001; Ręk and Osiejuk 2011a).

In this study, we investigated vocal NSD in the Corncrake, Crex crex, a non-learning (Brenowitz 1991), migrant rail species, Rallidae, in its natural environment. During the breeding season, Corncrakes inhabit wet, open areas with dense vegetation, where visual contact is very difficult (Green et al. 1997; Schäffer 1999). Corncrakes are sequentially polygamous, i.e. both males and females change partners between breeding attempts (Green et al. 1997). Males defend territories. The size of a territory ranges from 1 to more than 50 ha. The current knowledge of the dispersion and annual survival of the Corncrake is rudimentary. However, within-season movements of males, both within hundreds of metres and over distances of more than $10 \mathrm{~km}$, are not infrequent (Schäffer 1999). A return of ringed males to the same territories after 2 years has also been observed (B. Olech, personal communication).

At night, territorial Corncrake males give a very loud, bisyllabic and monotonous "cracking" call (Fig. 1). The function of this call appears to be equivalent to the function of song in songbirds, i.e. mate attraction, territory defence and announcement (Cramp and Simmons 1980). In contrast to the songs of many songbirds, this Corncrake call is seemingly very simple in structure. However, there is a higher degree of variation among individuals than within individuals in the temporal and frequency properties of 


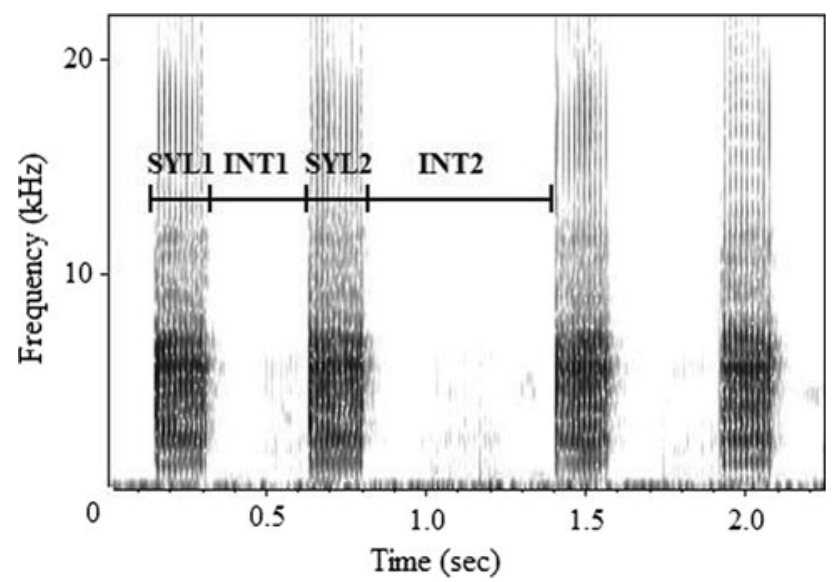

Fig. 1 Sonogram of Corncrake, Crex crex, call. The characteristics used for call measurement are shown: SYL1 first syllable, SYL2 second syllable, INT1 within-call interval, INT2 between-call interval

calls (Peake et al. 1998; Osiejuk and Olech 2004; Ręk and Osiejuk 2011a). Therefore, NSD is possible in the Corncrake, at least in theory. In particular, the individually characteristic pattern of intervals between successive maximal amplitude peaks within a syllable (termed pulseto-pulse duration, PPD; Peake et al. 1998) is often used by observers for the individual discrimination of males (Peake and McGregor 2001; Terry and McGregor 2002). However, the ability of Corncrake males to use PPD to discriminate among other males has never been confirmed.

In this study, we used interactive playback to experimentally examine the ability of Corncrakes to discriminate between the calls of familiar neighbours and unfamiliar strangers. We analysed the behaviour of territory holders during simulated intrusions by neighbours and strangers. Both vocal and nonvocal responses to the playback were considered.

\section{Methods}

\section{Study area}

The breeding period of the Corncrake in Poland extends from the middle of May to the middle of August (Green et al. 1997). Our study was conducted during the middle of the Corncrake breeding season, between 5 June and 1 July 2010. We tested 43 territorial males from two localities in central (Kampinoski National Park, 52 $19^{\prime} \mathrm{N}, 20^{\circ} 23^{\prime} \mathrm{E}$, $n=28$ ) and eastern Poland (Upper Nurzec River Valley, $52^{\circ} 36^{\prime} \mathrm{N}, 23^{\circ} 13^{\prime} \mathrm{E}, n=15$ ). Both localities are Important Birds Areas of international importance in Poland, with the size of the Corncrake population estimated as 110-140 males in Kampinoski National Park and 206-229 in the Upper Nurzec River Valley (Wilk et al. 2010). The Corncrakes were irregularly distributed in both localities.
The distance between a territorial male and its nearest neighbour ranged from 50 to $340 \mathrm{~m}$ (mean $=191 \mathrm{~m}$, $\mathrm{SD}=76.5 \mathrm{~m}$ ). The birds were not individually marked. We used PPD to confirm the identity of the males according to the method proposed by Peake et al. (1998).

Preparation of call stimuli and experimental protocol

To prepare neighbour call stimuli, we recorded calling males 1-3 days before the experiment. Recordings were made from a distance of ca. $10 \mathrm{~m}$ with an Edirol R-09 recorder and a Sennheiser ME 67 directional microphone with a K6 power unit (frequency response $40 \mathrm{~Hz}$ to $20 \mathrm{kHz})$. Recordings were made at night (2200-0400 hours local time). The exact locations of the calling males were determined with Garmin GPS receivers. Stranger stimuli were prepared with recordings from the local populations collected in 2007 and 2008 (Kampinoski National Park, $n=103$; Nurzec Valley, $n=58$ ). Recordings from Kampinoski National Park from 2007 and 2008 had a $22.05 \mathrm{kHz} / 16$ bit sampling rate. The rest of the recordings had a $44.1 \mathrm{kHz} / 16$ bit sampling rate. Therefore, all recordings were calibrated to the same digital quality $(22.05 \mathrm{kHz} / 16$ bit sampling) and were transferred to a PC workstation. The playbacks were digitally prepared to match a $95 \pm 5 \mathrm{~dB}$ signal pressure level (at $1 \mathrm{~m}$ ), an average natural amplitude for the Corncrake call (based on the authors' unpublished data). An earlier study of Corncrake vocalisation (Osiejuk et al. 2004) showed that the Corncrake call characteristic termed "rhythm" is individually variable within a single season and depends on the males' size and testosterone level. Rhythm is calculated as RHYTHM $=$ INT2/(SYL1 + INT1 + SYL2) (where SYL1 is the duration of the first syllable, SYL2 the duration of the second syllable, INT1 the duration of the withincall interval, and INT2 the duration of the between-call interval) and reflects the monotonous (low value of RHYTHM) or intermittent (high value of RHYTHM) character of calling, which can be detected easily by the human ear. Moreover, males respond more aggressively to the playback of an intermittent rhythm than to that of a monotonous rhythm, and males with intermittent calls are more aggressive (Ręk and Osiejuk 2010). To overcome this problem, we controlled rhythm in our experiment. To each male call used in the playback experiment, we randomly assigned a stranger male call with the same rhythm as the neighbour call used in the paired treatment. Thus, the rhythms of the neighbour and the stranger stimuli did not differ.

Avisoft SASLab Pro v.5.0.16 software (Specht 2007) was used for all the acoustic measurements and for the preparation of the song playback stimuli. To measure the temporal characteristics of the call (SYL1, SYL2, INT1, INT2, and RHYTHM), we used the following set of parameters: FFT 
length $=1,024$, Frame size $(\%)=25$, Window $=$ Hamming, and Temporal Overlap $=98.43 \%$. These parameter values produced a $112 \mathrm{~Hz}$ bandwidth with $21 \mathrm{~Hz}$ frequency and $0.72 \mathrm{~ms}$ time resolution (Specht 2007).

\section{Experimental design and playback procedure}

We used an interactive playback experiment consisting of two trials in which the call of a neighbour and the call of a stranger were presented (in random order) to the subject. A neighbour was defined as an individual with a territory bordering the territory of the subject (but no more distant than $300 \mathrm{~m}$ ), whereas a stranger was defined as a random male from the local population whose territory was more than $5 \mathrm{~km}$ distant from the subject and whose call was recorded during a different year. Both treatments (neighbour and stranger stimuli) were performed on the same night between 2230 and 0330 hours (local time). The time between treatments ranged from 0100 to 0350 hours. In this way, we avoided the influence of different weather conditions or changes in male status between treatments. Moreover, the use of this time period between successive trials was sufficient to allow the birds to return to their prestimulus levels of behaviour. We used 43 unique call recordings of different neighbours and 43 of different strangers to avoid pseudoreplication (Kroodsma 1989; Kroodsma et al. 2001). We did not control the presence of females or the stage of the breeding cycle. However, paired males are rarely vocally active, whereas males without females were found to sing during $95 \%$ of night-time checks (Tyler and Green 1996). Therefore, we may assume that the tested males were not paired. During each experiment, we simulated a situation in which a neighbour or stranger male appeared in the territory of the subject. Before the experiment, one person placed a speaker (SEKAKU WA-320, 20-W amplifier and 50-15 $000 \mathrm{~Hz}$ frequency range; Taichung, ROC Taiwan), connected to a Creative ZEN player, between the subject and the neighbour $(<0.5 \mathrm{~m}$ above ground, approximately $20 \mathrm{~m}$ from the subject). In the second treatment, the loudspeaker was also put between the subject and the neighbour, ca. $20 \mathrm{~m}$ from the subject, but in a different place (usually $20-30 \mathrm{~m}$ from the previous location). The observer did not know which playback (neighbour or stranger) was tested during the experiment. Simultaneously, the second person approached the neighbour. The proximity of a person caused the neighbour to remain silent during the experiment. Each trial lasted 6 min and consisted of two parts. In the first part of the trial, the male's behaviour was recorded for $1 \mathrm{~min}$ before the playback started. During the second part of the trial, the male's behaviour was recorded for 5 min during the playback. The stimulus was played if the subject was vocally active and was turned off $10 \mathrm{~s}$ after the termination of calling by the subject. The stimulus was played again only if the subject started calling again. This approach was chosen based on our previous observations of Corncrake behaviour during playback experiments. Corncrake males often fall silent after receiving the signal and begin calling again if they intend to locate the sender. In our experiment, the duration of the playback provided to the male ranged from $10 \mathrm{~s}$ (if the male was silent during the first and subsequent seconds of the experiment) to $5 \mathrm{~min}$ (if no pauses in calling were longer than $10 \mathrm{~s}$ in duration). Such an experimental approach, in which the tested male determines the length of the playback he receives, reflects the best natural mode of interaction between real rivals. A similar approach has been used successfully in playback experiments with Corncrake (Ręk and Osiejuk 2011b).

\section{Response measures and statistical analyses}

During the experiments, we observed the behaviour of the subject and recorded the calls given by the responding male (Edirol R-09 recorder and Sennheiser ME 67 directional microphone). Corncrake males display very strong territorial behaviour. The aggressive response to simulated territorial intrusion begins with an approach (on foot or in flight) towards the loudspeaker. The males also perform intermittent cracking calls, switch to soft gurgling-mewing calls and finally attack the loudspeaker (Ręk and Osiejuk 2010, 2011b). We chose to record 10 measures of response to assess the effects of the male's reaction towards the playback of neighbour and stranger stimuli. The measured responses described vocalisations, approaching the speaker, attacks and latencies of response (Table 1). Because it was not possible for the observer to precisely determine the distance between the speaker and the bird during the entire experiment, he always marked a 5-m radius around the speaker before the experiment and focused on detecting approaches closer to the speaker by the males. Attacks on the speaker were easy to detect even at night. Because the speaker was placed on a plastic box, it was easy to hear when the male hit the box.

The birds' responses during the experiments with playback were analysed with Generalized Estimating Equations (GEE), an extension of the quasi-likelihood approach that permits the analysis of nested structure in an experimental design (two treatments for each male) and allows the analysis of data with different distribution patterns and incorporating additional predictors. We used binomial dependent variables (with values of 0 or 1 ) to describe the differences in attacks on the speaker, the latency to the first approach within $5 \mathrm{~m}$, the total time within $5 \mathrm{~m}$ of the speaker and the number of gurgling-mewing calls. The value 1 indicated the following outcomes: more frequent attacks on the speaker, a more rapid approach to within $5 \mathrm{~m}$ of the speaker, more time spent 
Table 1 Measures of response to playback of Corncrake, Crex crex, calls of a neighbour and a stranger

\begin{tabular}{llccc}
\hline Respond measured & $n$ & Neighbour stimulus & Stranger stimulus & Mean differences \\
\hline Duration of SYL 1 (ms) & 40 & $168 \pm 16.4$ & $172 \pm 26.1$ & $13 \pm 17.9$ \\
Duration of SYL 2 (ms) & 40 & $187 \pm 16.7$ & $189 \pm 19.2$ & $9 \pm 8.8$ \\
Duration of INT 1 (ms) & 40 & $368 \pm 38.9$ & $372 \pm 58.2$ & $35 \pm 72.1$ \\
Duration of INT 2 (ms) & 39 & $669 \pm 122.8$ & $679 \pm 161.5$ & $105 \pm 100.1$ \\
RHYTHM & 39 & $0.93 \pm 0.16$ & $0.92 \pm 0.19$ & $193 \pm 150.2$ \\
Total number of syllables during 5 min playback & 43 & $182 \pm 147.5$ & $1.07 \pm 2.59$ & $100 \pm 104.2$ \\
Number of gurgling-mewing calls & 43 & $0.79 \pm 1.81$ & $90 \pm 95.0$ & $2.35 \pm 1.46$ \\
Latency to first approach within 5 m (s) & 43 & $59 \pm 78.4$ & $85 \pm 92.7$ & $94 \pm 66.8$ \\
Total time within 5 m of speaker (s) & 43 & $50 \pm 69.0$ & $0.51 \pm 0.91$ & $90 \pm 62.3$ \\
Number of attacks of the speaker & 43 & $0.16 \pm 0.57$ & $1.50 \pm 0.94$ \\
\hline
\end{tabular}

The mean differences in the male's responses between treatments were calculated. The latency to approach to a distance less than $5 \mathrm{~m}$ from the loudspeaker was transformed by subtracting the original values from the maximum possible value ( $300 \mathrm{~s}$ ), so that higher values would indicate a more rapid approach

Values are mean \pm standard deviation

within $5 \mathrm{~m}$ of the speaker and the more frequent performance of gurgling-mewing calls. We fitted the data with a binomial distribution (logit link function). To describe the remaining vocal responses, we measured the durations of SYL1, SYL2, INT1 and INT2, we calculated RHYTHM, and we counted the numbers of syllables (SYL1 + SYL2) performed during a 5-min playback experiment. Corncrake males may make relatively long pauses between calls. These longer pauses increase the value of INT2 considerably. In this paper, we focused on continuous series of calls. Therefore, we arbitrarily decided that a series was completed if INT2 exceeded $2 \mathrm{~s}$. This value was chosen based on measurements of hundreds of naturally vocalising males from Polish populations, where the longest second interval was $1.92 \mathrm{~s}$ in length.

We measured all Corncrake calls performed during the experimental procedure and calculated the mean value of each variable. The mean values were used in subsequent analyses. The SYL1, SYL2, INT1, INT2 and RHYTHM variables were fitted with a gamma distribution (log-link function), and the numbers of syllables performed during playback were fitted with a negative binomial distribution (log-link function). We used the following categorical predictor variables in all the models: playback treatments (neighbour or stranger), locality (Kampinoski National Park or Nurzec River Valley) and order of playback (neighbour first vs. stranger first). Quasi-likelihood under the independence model criterion (for choosing the best correlation structures) and its corrected version (for choosing the best subsets of predictors) were used to select the model parameters. In all, we fitted 10 independent models. The best model was chosen for each measure of response during the experiments.

Additionally, to describe the general vocal reaction towards the call of the intruder, we compared the characteristics of the calls given $1 \mathrm{~min}$ before the beginning of the playback and during $5 \mathrm{~min}$ of the playback experiment. We calculated the mean values for each period of time. We then performed paired $t$ tests (mean values of variables: SYL1, SYL2, INT1, INT2 and RHYTHM) and a Wilcoxon paired test (variable: number of syllables (SYL1 + SYL2)/ $1 \mathrm{~min}$ ). Males that were calling before the experiment and were silent or uttered fewer than 5 calls during the experiment were excluded from the comparison of SYL1, SYL2, INT1, INT2 and RHYTHM. A Bonferroni correction for the $p$ value was incorporated. All $p$ values are two-tailed. All the statistical analyses were performed in PASW Statistics 18 .

\section{Results}

We used interactive playbacks to determine whether Corncrake males $(n=43)$ distinguish between the calls of a familiar neighbour and an unfamiliar stranger. We found significant differences in the behavioural reactions (number of attacks on the speaker, time spent less than $5 \mathrm{~m}$ from the speaker and latency to approach less than $5 \mathrm{~m}$ from the speaker) and no differences in the vocal responses towards the playbacks of the neighbour and stranger calls. Differences in playback duration among treatments were not significant (paired $t$ test; $t=0.188, d f=42, p=0.857$ ).

\section{Behavioural response}

During the playback experiments, 26 males approached to a distance less than $5 \mathrm{~m}$ from the speaker, and 14 of them attacked the speaker. Seven males approached to a distance greater than $5 \mathrm{~m}$ the speaker, and 11 males did not approach the speaker during both treatments. The GEE showed significant differences between the behavioural 
responses to the playbacks of the calls of the familiar neighbour and the unfamiliar stranger (Table 2). During the playbacks of the stranger stimulus, the territory holders attacked the speaker more frequently, approached to a distance less than $5 \mathrm{~m}$ more rapidly, and spent more time close to the speaker (Table 1; Fig. 2). In all cases, the influence of the sequence of playback (neighbour first vs. stranger first) or population was not significant (Table 2).

\section{Vocal response}

Only 3 males did not perform cracking calls during the 5-min playback stage of the experiments. Low-amplitude gurgling-mewing calls were performed by 10 males towards the neighbour stimulus and by 13 males towards the stranger stimulus. This signal was not observed before the playback experiment, and only two males performed it after the experiment. We did not find significant differences between the vocal responses towards a neighbour and a stranger stimulus (in all GEE models $p>0.05$ ) (more details in Table 3). However, we found that many temporal parameters of the calls changed after the start of the playback regardless of the stimuli used. Paired tests showed significant differences between the duration of INT1, INT2, and RHYTHM and numbers of syllables $((\mathrm{SYL} 1+\mathrm{SYL} 2) / 1 \mathrm{~min})$ performed before and during the playback. However, the differences in SYL1 (after a Bonferroni adjustment) and SYL2 were not significant (Table 4). During the intruder playback, the Corncrake males significantly increased INT1, INT2, and RHYTHM and performed fewer syllables than before the playback. Overall, the birds responding to playbacks called less intensively and with a more intermittent rhythm compared to natural vocalisations undisturbed by playback.

\section{Discussion}

The results of this study demonstrated the ability of Corncrake males to discriminate between the calls of neighbours and strangers. To the best of our knowledge, this study is the first to experimentally demonstrate NSD in the order Gruiformes and is one of only a few studies showing that NSD occurs in non-learning bird species. Our results are consistent with the "dear enemy phenomenon" (Fisher 1954) and also suggest that Corncrakes use NSD to maintain the cost of territorial defence at a reasonable level. The more rapid approach to the speaker, the greater amount of time spent near the speaker and, particularly, the greater number of attacks on the speaker during the playback of the stranger call unambiguously indicated the occurrence of a more aggressive response towards the intrusion of a stranger than towards a neighbour. In Corncrakes, a stranger male should clearly represent a more serious threat than a neighbour to a territory holder. It is known that territorial Corncrake males perform visits to the territory of neighbours, especially if the neighbours are close. During such visits, the intruders tend to be silent, apparently to prevent confrontation (Skliba and Fuchs 2004). Moreover, the males are silent if they are paired and call intensely if they are not accompanied by a female (Tyler and Green 1996). Therefore, the appearance of the calling familiar neighbour in the territory of a calling resident is most likely a mistake in location by the intruder, whereas the appearance of an unknown stranger should be a more serious threat.

In birds, vocal communication is very important in territorial interactions (Catchpole and Slater 2008). Changes in the number of trills and whistles (Sprau et al. 2010), number of calls and songs (Lovell and Lein 2005; Hyman

Table 2 Results of generalized estimating equations showing behavioural responses towards neighbour and stranger stimuli

\begin{tabular}{|c|c|c|c|c|c|c|c|c|c|}
\hline \multirow{2}{*}{$\begin{array}{l}\text { Dependent variable } \\
\text { Parameter }\end{array}$} & \multicolumn{3}{|c|}{ Attack of the speaker } & \multicolumn{3}{|c|}{ Approach within $5 \mathrm{~m}$ of speaker } & \multicolumn{3}{|c|}{ Total time within $5 \mathrm{~m}$ of speaker } \\
\hline & Wald $\chi^{2}$ & $d f$ & $P$ & Wald $\chi^{2}$ & $d f$ & $P$ & Wald $\chi^{2}$ & $d f$ & $P$ \\
\hline Intercept & 1.78 & 1 & 0.182 & 0.01 & 1 & 1.000 & 0.01 & 1 & 1.000 \\
\hline Treatment & 9.40 & 1 & 0.002 & 6.40 & 1 & 0.011 & 4.68 & 1 & 0.031 \\
\hline Sequence & 0.39 & 1 & 0.533 & 0.19 & 1 & 0.665 & 0.84 & 1 & 0.358 \\
\hline Population & 1.78 & 1 & 0.182 & 0.01 & 1 & 1.000 & 0.01 & 1 & 1.000 \\
\hline QIC/QICC & \multicolumn{3}{|c|}{$24.76 / 26.01$} & \multicolumn{3}{|c|}{$63.81 / 63.81$} & \multicolumn{3}{|c|}{$66.86 / 66.86$} \\
\hline
\end{tabular}

Models including treatment (neighbour vs. stranger), population (Kampinoski National Park vs. Nurzec River Valley) and sequence of stimulus (neighbour first vs. stranger first). Dependent variables are shown on a binomial scale (values of 0 or 1 ), where 1 indicates more frequent attacks on the speaker, a more rapid approach to within $5 \mathrm{~m}$ of the speaker or more time spent within $5 \mathrm{~m}$ of the speaker. Wald statistics and $P$ values are given

OIC Quasi Likelihood under Independence Model Criterion; QICC Corrected Quasi Likelihood under Independence Model Criterion 

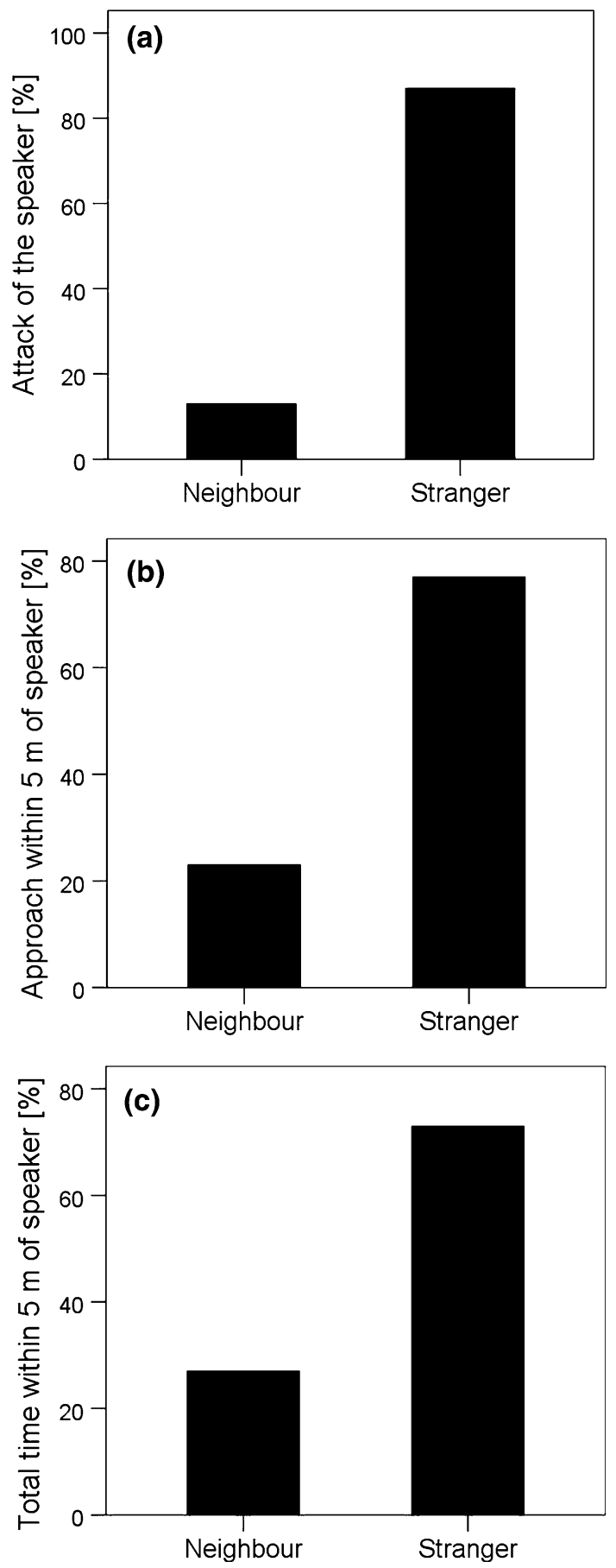

Fig. 2 Comparison of the binomial responses to playback of neighbours' and strangers' calls. Only the males that showed any response, at least for one treatment, were considered. a The percentage of males that attacked the speaker more often during the neighbour and stranger stimuli $(n=14)$; $\mathbf{b}$ the percentage of males that approached more rapidly within $5 \mathrm{~m}$ of the speaker during the neighbour and stranger stimuli $(n=26)$; $\mathbf{c}$ the percentage of males that spent more time within $5 \mathrm{~m}$ of the speaker $(n=26)$

and Hughes 2006), soft songs (Ballentine et al. 2008), frequency bandwidth (DuBois et al. 2009) or length of the song (Ríos-Chelén and Garcia 2007) can indicate a more or less aggressive motivation of the sender. The broadcast call of the Corncrake is simple because there is no repertoire variation. However, the male may still modify the intensity and rhythm of the call. We found that Corncrake males increased the rhythm of calling and performed fewer syllables per $1 \mathrm{~min}$ during the playback experiment than before the playback. A change to a more intermittent level of rhythm signals a more aggressive motivation of the sender (Ręk and Osiejuk 2010). In contrast, a decrease in the number of calls during aggressive interactions can be explained in two different ways. First, males cannot move and call simultaneously. Therefore, they simply do not call when approaching the speaker. Second, it could be difficult to send and receive such loud signals (even exceeds $95 \mathrm{~dB}$ SPL at $1 \mathrm{~m}$; Ręk and Osiejuk 2011a) and simultaneously try to precisely localise the intruder. Corncrake males perform gurgling-mewing calls in addition to cracking calls. We observed gurgling-mewing calls during the playback (26 cases) but never before the playback. Gurgling-mewing calls appear to be the equivalent of quiet or soft songs in passerine birds and are also a signal of the aggressive motivation of males (Ręk and Osiejuk 2011b). Both the cracking and the gurgling-mewing calls indicate an increase in the aggressiveness of the territory holder during the playback experiment. However, the vocal responses towards the intrusion of a neighbour and of a stranger are the same. Our results suggest that the Corncrake call is a first line of defence (Catchpole and Slater 2008). Males signal aggression towards both intruders, but they assume the risk of attack significantly more often towards a stranger. The lack of differences in very simple call structure responses and the presence of clear differences in other behavioural responses (i.e. approaching or attacking the speaker) demonstrates that the absence of a differential response does not imply the absence of discrimination. This finding is very important for the interpretation of negative results in NSD experiments.

The development of NSD in non-learning species with very simple calls is an important topic. Whether or not songs or calls are learned, individually specific call characteristics must exist to make NSD possible (Falls 1982; Stoddard 1996). Individuals should also be able to distinguish and remember the calls of neighbours. Songbirds develop song through learning from conspecifics, and this process undoubtedly affects NSD by shaping repertoire sizes, the level of song sharing and other outcomes of cultural transmission (Stoddard 1996). However, in the Corncrake, as in the other Gruiformes, song learning is absent (Brenowitz 1991). Thus, any of the call characteristics that contribute to an individual vocal signature must arise independently of learning processes. Nevertheless, Corncrake males must also learn, in the sense that learning and remembering the calls of other males is a necessary 
Table 3 Results of generalized estimating equations showing vocal responses towards neighbour and stranger stimulus

\begin{tabular}{|c|c|c|c|c|c|c|c|c|c|}
\hline \multirow[t]{2}{*}{ Dependent variable } & \multicolumn{2}{|l|}{ Intercept } & \multicolumn{2}{|c|}{ Treatment } & \multicolumn{2}{|l|}{ Sequence } & \multicolumn{2}{|c|}{ Population } & \multirow[t]{2}{*}{ QIC/QICC } \\
\hline & Wald $\chi^{2}$ & $P(d f=1)$ & Wald $\chi^{2}$ & $P(d f=1)$ & Wald $\chi^{2}$ & $P(d f=1)$ & Wald $\chi^{2}$ & $P(d f=1)$ & \\
\hline SYL1 & $100,393.28$ & $<0.001$ & 1.28 & 0.258 & 3.90 & 0.048 & 0.14 & 0.708 & $9.7 / 9.1$ \\
\hline SYL2 & $119,200.18$ & $<0.001$ & 1.31 & 0.252 & 1.69 & 0.194 & 0.01 & 0.913 & $9.6 / 8.7$ \\
\hline INT1 & $145,858.95$ & $<0.001$ & 0.13 & 0.721 & 1.83 & 0.176 & 3.54 & 0.060 & $9.0 / 9.2$ \\
\hline INT2 & $62,329,28$ & $<0.001$ & 0.13 & 0.716 & 0.54 & 0.464 & 0.70 & 0.403 & $11.3 / 11.4$ \\
\hline RHYTHM & 9.66 & 0.002 & 0.06 & 0.799 & 1.23 & 0.268 & 0.09 & 0.764 & $10.6 / 11.0$ \\
\hline N. of syl. & $2,828.91$ & $<0.001$ & 0.63 & 0.427 & 3.11 & 0.078 & 3.15 & 0.076 & $114.7 / 118.0$ \\
\hline F. of g-m calls & 1.11 & 0.292 & 1.04 & 0.308 & 3.83 & 0.050 & 1.11 & 0.292 & $44.8 / 45.1$ \\
\hline
\end{tabular}

Models including treatment (neighbour vs. stranger), population (Kampinoski National Park vs. Nurzec River Valley) and sequence of stimulus (neighbour first vs. stranger first). SYL1, SYL2, INT1, INT2 and RHYTHM were fitted using a gamma distribution (log link function). The number of syllables ( $N$. of syl.) was fitted using a negative binomial distribution (log-link function), and the frequency of performing gurglingmewing calls ( $F$. of $g-m$ calls) was fitted using a binomial distribution (logit function). Wald statistics and $P$ values are given

OIC Quasi Likelihood under Independence Model Criterion; QICC Corrected Quasi Likelihood under Independence Model Criterion

Table 4 Results of paired tests showing general vocal reaction toward call of intruder

\begin{tabular}{lccrrr}
\hline Call characteristic & Before mean $( \pm$ SE) & During mean $( \pm$ SE $)$ & T/Z & $d f$ \\
\hline SYL1 & $165(1.6)$ & $170(2.4)$ & -2.615 & 81 & $0.011^{\mathrm{a}}$ \\
SYL2 & $186(1.9)$ & $188(2.0)$ & -1.833 & 81 \\
INT1 & $356(2.7)$ & $369(5.5)$ & -3.042 & 81 & $0.070^{\text {a }}$ \\
INT2 & $528(10.5)$ & $674(15.8)$ & -11.856 & 81 & $<0.003^{\mathrm{a}}$ \\
RHYTHM & $0.75(0.016)$ & $0.93(0.019)$ & -10.844 & 81 \\
N. of SYL & $83(29.2)$ & $37(29.6)$ & -7.536 & 85 & $<0.001^{\mathrm{a}}$ \\
\hline
\end{tabular}

Mean values and standard errors of call characteristics before start and during playback experiment are given. After Bonferroni's adjustment, tests with $P$ value lesser than 0.008 are significant

${ }^{\text {a }} t$ test

b Wilcoxon test

condition for distinguishing between the calls at a later time. The time window during which males learn and memorise the calls of their neighbours, as well as the call characteristics that are used for individual discrimination, are still unknown. It is probable that Corncrake males use between-individual variation in PPD characteristics for individual discrimination. This call characteristic is individually specific, does not vary during the life of the bird and is potentially very useful for individual discrimination (Peake et al. 1998). Moreover, information contained in PPD is not lost during transmission in the natural habitat (Ręk and Osiejuk 2011a). However, no direct proof exists that Corncrakes actually use PPD for individual discrimination. It is noteworthy that pulses are, on average, $3-5 \mathrm{~ms}$ in length and are separated by intervals of $4-8 \mathrm{~ms}$ (Peake et al. 1998). Therefore, the intervals between following pulses are very small (ca. 7-13 ms), and it could be difficult for males to distinguish such small differences (Dooling 2004). Alternatively, Fitch and Kelley (2000) showed that, in Gruiformes, formants provide acoustic cues to individuality and body size. Moreover, Suthers (1994) suggested that formant frequencies are a potential basis of acoustic recognition in the oilbird, Steatornis caripensis, a colonial bird species that inhabits dark caves. Unfortunately, formant dispersion in the Corncrake call has not yet been studied. Therefore, there is a need for further research to determine the call characteristics responsible for coding individual identity in the Corncrake.

Our results show that Corncrake males can use calls to discriminate between neighbours and strangers. The acoustic channel appears to be the most important sensory channel for this species because it allows communication at night, over long distances and in dense vegetation. In these circumstances, visual contact is virtually impossible. Therefore, we suppose that NSD by calls in the Corncrake may substantially reduce the costs of territory defence by avoiding unnecessary conflicts (Fisher 1954). However, the call characteristics used by males for NSD are still 
unknown. Whether females also use information about male identity (and, if so, how) remains to be determined.

Acknowledgments We thank P. Ręk and K. Jurczak for their help with the fieldwork. The study was conducted thanks to permission given by the Director of Kampinoski National Park. This study was conducted in full compliance with current Polish law.

Open Access This article is distributed under the terms of the Creative Commons Attribution License which permits any use, distribution, and reproduction in any medium, provided the original author(s) and the source are credited.

\section{References}

Ballentine B, Searcy WA, Nowicki S (2008) Reliable aggressive signalling in swamp sparrows. Anim Behav 75:693-703

Brenowitz EA (1991) Evolution of the vocal control system in the avian brain. Semin Neurosci 3:339-407

Briefer E, Aubin T, Lehongre K, Rybak F (2008a) How to identify dear-enemies: the group signature in the complex song of the skylark Alauda arvensis. J Exp Biol 211:317-326

Briefer E, Rybak F, Aubin T (2008b) When to be a dear enemy: flexible acoustic relationships of neighbouring skylarks, Alauda arvensis. Anim Behav 76:1319-1325

Brown JL (1964) The evolution of diversity in avian territorial systems. Wilson Bull 76:160-169

Catchpole CK, Slater PJB (2008) Bird song. Biological themes and variations, 2nd edn. Cambridge University Press, Cambridge

Clark JA, Boersma PD, Olmsted DM (2006) Name that tune: call discrimination and individual recognition in Magellanic penguins. Anim Behav 72:1141-1148

Cramp S, Simmons KEL (1980) The birds of the Western Palearctic, vol 2. Oxford University Press, Oxford

Davis MS (1987) Acoustically mediated neighbor recognition in the North American bullfrog, Rana catesbeiana. Behav Ecol Sociobiol 21:185-190

Dooling R (2004) Audition: can birds hear everything they sing? In: Marler P, Slabbekoorn H (eds) Nature's music: the science of birdsong. Academic, San Diego, pp 209-228

DuBois AL, Nowicki S, Searcy WA (2009) Swamp sparrows modulate vocal performance in an aggressive context. Biology Lett 5:163-165

Falls JB (1982) Individual recognition by sound in birds. In: Kroodsma DE, Miller EH (eds) Ecology and evolution of acoustic communication in birds. Academic, New York, pp 237-278

Falls JB, McNicholl MK (1979) Neighbor-stranger discrimination by song in male blue grouse. Can J of Zool 57:457-462

Fisher J (1954) Evolution and bird sociality. In: Huxley J, Hardy HC, Ford EB (eds) Evolution as a process. Allen and London University Press, London, pp 71-83

Fitch WT, Kelley JP (2000) Perception of vocal tract resonances by whooping cranes Grus americana. Ethology 106:559-574

Green ER, Rocamora G, Schäffer N (1997) Populations, ecology and threats to the corncrake Crex crex in Europe. Vogelwelt 118: $117-134$

Hardouin LA, Tabel P, Bretagnolle V (2006) Neighbour-stranger discrimination in the little owl, Athene noctua. Anim Behav $72: 105-112$
Hyman J, Hughes M (2006) Territory owners discriminate between aggressive and nonaggressive neighbours. Anim Behav 72: 209-215

Jouventin P, Aubin T, Lengagne T (1999) Finding a parent in a king penguin colony: the acoustic system of individual recognition. Anim Behav 57:1175-1183

Kroodsma DE (1989) Suggested experimental designs for song playbacks. Anim Behav 37:600-609

Kroodsma DE, Byers BE, Goodale E, Johnson S, Liu W-C (2001) Pseudoreplication in playback experiments, revisited a decade later. Anim Behav 61:1029-1033

Leiser JK (2003) When are neighbours 'dear enemies' and when are they not? The responses of territorial male variegated pupfish, Cyprinodon variegatus, to neighbours, strangers and heterospecifics. Anim Behav 65:453-462

Lovell SF, Lein MR (2004) Neighbor-stranger discrimination by song in a suboscine bird, the alder flycatcher, Empidonax alnorum. Behav Ecol 15:799-804

Lovell SF, Lein MR (2005) Individual recognition of neighbors by song in a suboscine bird, the alder flycatcher Empidonax alnorum. Behav Ecol Sociobiol 57:623-630

Mackin WA (2005) Neighbor-stranger discrimination in Audubon's shearwater (Puffinus l. lherminieri) explained by a "real enemy" effect. Behav Ecol Sociobiol 59:326-332

Mager JN, Walcott C, Piper WH (2010) Common Loons can differentiate yodels of neighboring and non-neighboring conspecifics. J Field Ornithol 81:392-401

Osiejuk TS, Olech B (2004) Amplitude spectra of corncrake calls: what do they signalise? Anim Biol 54:207-220

Osiejuk TS, Olech B, Ratyńska K, Owsiński A, GromadzkaOstrowska J (2004) Effect of season, plasma testosterone and body size on corncrake (Crex crex) call rhythm. Ann Zool Fenn 41:647-659

Peake TM, McGregor PK (2001) Corncrake Crex crex census estimates: a conservation application of vocal individuality. Anim Biodivers Conserv 24:81-90

Peake TM, McGregor PK, Smith KW, Tyler G, Gilbert G, Green RE (1998) Individuality in corncrake Crex crex vocalization. Ibis 140:120-127

Radford AN (2005) Group-specific vocal signatures and neighbourstranger discrimination in the cooperatively breeding green woodhoopoe. Anim Behav 70:1227-1234

Rebbeck M, Corrick R, Eaglestone B, Stainton C (2001) Recognition of individual European Nightjars Caprimulgus europaeus from their song. Ibis 143:468-475

Ręk P, Osiejuk TS (2010) Sophistication and simplicity: conventional communication in a rudimentary system. Behav Ecol 21: 1203-1210

Ręk P, Osiejuk TS (2011a) No male identity information loss during call propagation through dense vegetation: the case of the corncrake. Behav Process 86:323-328

Ręk P, Osiejuk TS (2011b) Non-passerine bird produces soft calls and pays retaliation cost. Behav Ecol 22:657-662

Ríos-Chelén AA, Garcia CM (2007) Responses of a sub-oscine bird during playback: effects of different song variants and breeding period. Behav Process 74:319-325

Schäffer N (1999) Habitatwahl und Partnerschaftssystem von Tüpfelralle Porzana porzana und Wachtelkönig Crex crex. Ökol Vögel 21:1-267

Skliba J, Fuchs R (2004) Male corncrakes Crex crex extend their home ranges by visiting the territories of neighbouring. Bird Study 51:113-118

Specht R (2007) Avisoft-SASLab Pro ver. 4.39. Sound analysis and synthesis software. Avisoft Bioacustics, Berlin 
Sprau P, Roth T, Schmidt R, Amrhein V, Naguib M (2010) Communication across territory boundaries: distance-dependent responses in nightingales. Behav Ecol 21:1011-1017

Stoddard PK (1996) Vocal recognition of neighbors by territorial passerines. In: Kroodsma DE, Miller EH (eds) Ecology and evolution of acoustic communication in birds. Cornell University Press, Ithaca

Suthers RA (1994) Variable asymmetry and resonance in the avian vocal tract: a structural basis for individually distinct vocalizations. J Comp Physiol A 175:457-466

Temeles EJ (1990) Northern harriers on feeding territories respond more aggressively to neighbors than to floaters. Behav Ecol Sociobiol 26:57-63
Temeles EJ (1994) The role of neighbours in territorial systems: when are they 'dear enemies'? Anim Behav 47:339-350

Terry AMR, McGregor PK (2002) Census and monitoring based on individually identifiable vocalizations: the role of neural networks. Anim Conserv 5:103-111

Tyler GA, Green RE (1996) The incidence of nocturnal song by male corncrakes Crex crex is reduced during pairing. Bird Study 43:214-219

Wilk T, Jujka M, Krogulec J, Chylarecki P (2010) Important bird areas of international importance in Poland. OTOP, Marki 